\title{
TALLER DE CREACIÓN LITERARIA PABLO NERUDA, HACIA UN DESARROLLO SOSTENIBLE DEL TALENTO ARTÍSTICO UNIVERSITARIO
}

\author{
Carlos Chacón Zaldivar ${ }^{1}$
}

\begin{abstract}
Resumen: La realidad sociocultural que vive el país y el creciente desarrollo cultural que caracteriza a la Atenas de Cuba, exigen al Movimiento de Artistas Aficionados de la Universidad de Matanzas en Cuba, un despliegue armonioso con el aprovechamiento de sus fortalezas académicas y las oportunidades de su entorno para poder influir positivamente hacia adentro y hacia afuera de la comunidad universitaria. Así el movimiento de jóvenes escritores de esta casa de altos estudios busca profundizar su labor creativa y a la vez socializar más sus producciones literarias a partir del proyecto sociocultural Taller de Creación Pablo Neruda.
\end{abstract}

Palabras claves: proyecto, aficionados, creación literaria, socialización.

\section{INTRODUCCIÓN}

En los últimos años han ocurrido profundas transformaciones en la universidad y en sus vínculos con el entorno sociocultural. Son muchos los pensadores e investigadores, cuyas teorías y concepciones educativas, han influido y siguen estimulando la labor extensionistas. En tal sentido, es digno recordar la obra de Paulo Freire, quien proclamó basar la labor extensionista desde la dialogicidad, como una necesidad de entendimiento entre los implicados a un mismo nivel de saberes, cuestionamiento que se verifica y amplifica en las tesis del ya clásico ensayo ¿Extensión o comunicación? La concientización en el medio rurat, allí está la profunda comunicación de los sujetos interlocutores con sus potenciales mensajes y saberes a compartir.

La profundización en torno a la promoción cultural como metodología de intervención y su implementación, a partir de un diagnóstico y de las características y circunstancias específicas de un sitio seleccionado para la aplicación, han

1 Universidad de Matanzas - Cuba.

2 En ese texto reafirmaba que "el diálogo es el encuentro amoroso de los hombres que, mediatizados por el mundo-lo pronuncian-, esto es, lo transforman y transformándolo, lo humanizan, para la humanización de todos. 
determinado también la interrelación de todo un proceso que se va especificando en la medida en que se prioriza el sector de la intervención. Sin embargo, junto a la promoción se han venido desplegando los procesos de gestión cultural.

Para Bayardo (2001, p. 3), "la gestión viene a reformular nociones anteriores sobre un área similar, pero no idéntica como la promoción, la planificación, o la administración, en relación con proyectos e instituciones. Reafirma que el debate no está en la gestión solo, sino en los modos y conceptualizaciones con que es concebida".

Tal referencia permite focalizar una práctica cultural desde los elementos incluidos, con énfasis en el acceso, la distribución, los flujos informativos y el vínculo a la política cultural, aspectos que no son abordados en la cita, pero necesarios para repensar la problemática de la creatividad literaria y sus resultados, en las funciones de obra artística, medio de comunicación y producto de consumo cultural.

Amaya Quincoces (2008, p.23) incorpora el término de gestión artístico cultural y afirma que "es un acto de creatividad, debido a que cada gestor debe apropiarse de los enfoques, métodos y técnicas que mejor sirvan a su quehacer, posibilidades y contexto". Hay aquí una aportación pertinente, que profundiza en el diseño de las manifestaciones, y la puesta de sus productos en el consumo, aunque difiere de la creación literaria, aporta ideas para concebir los proyectos en el entorno comunitario.

Borbón (2015, p. 2), indica que la gestión "se plantea retos y problemas para revalorizar los lazos y el sentido de vivir juntos, en tanto las políticas culturales obligan a salir del modelo difusionista para ingresar en un modelo comunicativo".

Véase que la autora asume el proceso desde una perspectiva más contemporánea, en tanto su juicio rechaza los enfoques difusionistas que promueven las "bellas artes" mediante la apreciación, y ubica su labor en la búsqueda de mejores condiciones de vida y el bienestar de los que reciben los esfuerzos de los agentes culturales.

Explica que esas transformaciones supondrían ubicar las dinámicas culturales en los espacios creativos, con lo cual facilita a los sujetos elegir las opciones desde sus experiencias, ideas que no solo humanizan la gestión, sino que exigen a los agentes potenciar los tiempos creativos, con dinámicas participativas y formas de comunicación, en condiciones de respeto, dignidad y solidaridad.

Es una valoración que acopla lo instrumental, la creación y el bienestar social, por tanto cuestiona los lazos entre la cultura y el proceder político transformador, lo que ubica tales presupuestos en una zona de interés para los procesos culturales. Los juicios anteriores con sus específicas visiones en el campo de la gestión, abordan puntos de vista y rasgos que enriquecen lo teórico metodológico, pero también tributan a la conformación de estrategias, por lo cual facilitan el diseño de herramientas y procedimientos, para lograr mejores desempeños en el accionar de los agentes, lo que propiciaría un impacto de la promoción literaria en la convivencia de grupos y comunidades afines a una tradición. 
En los referentes teóricos acerca de las estrategias se revisaron los pronunciamientos de Bower y Doz (1978), Mintzberg y Waters (1985), Menguzzato (1989) y Eduardo Vázquez (2011) ya que señalan elementos claves que deberán ser tenidos en cuenta para diseñar proyectos desde la promoción.

Según E. Eduardo Vázquez (comunicación personal, 12 de octubre, 2011), "el diseño de una estrategia debe partir de la práctica escogida y su lugar, así en el campo cultural será necesario identificar las dinámicas que lo caracterizan, pues revelan la complejidad del objeto de estudio y las posibilidades de incorporar saberes para su abordaje".

En tal sentido, tales juicios son claves para estructurar un proyecto sociocultural desde la manifestación literaria, pues la estudiosa insiste en la concreción de una práctica o proceso y en su derivación al campo científico, integra un grupo de factores para tal abordaje, enfatiza en las posibilidades de cambio y sitúa el proceder estratégico dentro del campo cultural. Por tanto, su metódica permite conocer las capacidades internas del objeto seleccionado y las vías para rearticular el mismo con el entorno.

Así el diseño de un proyecto socioliterario según estos basamentos debe prever la influencia que ejercen las circunstancias sociales, culturales y tecnológicas sobre el entorno, en dependencia de la organización y sus prácticas, ya que son determinantes los objetivos y su relación con las metas. Deberán adoptarse las políticas que aseguren alcanzar dichas metas.

En el marco de este análisis se integra de manera específica la posibilidad de acceder a la literatura como a un espacio legítimo desde la comunicación, cuya ubicación facilita al investigador una mirada diferente sobre el quehacer literario y sus autores.

En esta línea, se han realizado diversos estudios que enfocan tanto al emisor como al receptor de las expresiones literarias. Lo cierto es que en las últimas décadas se ha producido un ahondar en la pragmática, cuyos términos apropiación, cooperación, actos de habla y recepción, son elementos que argumentan la cuestión.

En notas para un debate teórico Karam (2006), delimita el papel y los vínculos del emisor literario e identifica los segmentos (emisor-mensaje/ mensajereceptor), que despliegan cadenas de transmisión con sus agentes mediadores. Lo cual permite analizar cómo se generan variantes comunicativas que necesitan del quehacer lectoral, con sus análisis, discusiones y comentarios, en los cuales comienza a mediar la crítica especializada.

En tal criterio se distinguen aristas de la relación emisor-texto-lector, pero no refiere el impacto que ejerce el contexto sobre la escritura producida, dado que el escritor convive en grupos acorralados por las dificultades, las mediaciones y un entorno dominante, aspectos que pueden argumentar la diversidad de formas y expresiones literarias.

En este contexto, la promoción literaria se ubica dentro de la promoción cultural, en tanto ella le brinda principios generales, los rasgos y las formas de 
actuación que asumen los sujetos en las manifestaciones y expresiones culturales, dentro de contextos específicos.

Por un lado, las apreciaciones de los investigadores cubanos y las referencias delimitadas anteriormente aportan conocimientos específicos al quehacer literario, y por otro, su caracterización incluye los intercambios entre emisor, texto y receptor ya argumentados para identificar a la comunicación literaria desde la pragmática.

Según la sociología de Bourdieu (1990, p.19) las luchas literarias se desarrollan para alcanzar el "poder de decir con autoridad quién está autorizado a llamarse autor; o, si se prefiere, el monopolio del poder de consagración de los productores o de los productos (se está en un universo de creencia y el escritor consagrado es el que tiene el poder de consagrar y de obtener la adhesión cuando consagra a un autor o una obra -mediante un prefacio, una crítica laudatoria, un premio, etc.)".

Graziella Pogolotti (2000, p.2) hace referencia a una concepción más abarcadora de la promoción literaria, que sitúa la "intensificación de una vida literaria que pueda permear a la sociedad; el tránsito desde una creación individual a su repercusión social y en el alcance que tenga para ese lector que hay que conquistar". Adviértase en los referentes indicados por la ensayista su forma de enlazar lo individual y lo social, para centrar la formación del lector y fomentar la vida literaria, con una positiva repercusión en el plano social.

Reconoce Pogolotti como otro elemento la evaluación que debe hacer la crítica especializada, en tanto debe activar el diálogo entre el autor y el lector, pero además ubicar relaciones del mundo literario con las circunstancias sociales. Describe así nuevas conexiones entre diversos protagonistas del ámbito literario, hasta enfatizar que el crítico está llamado a opinar regularmente sobre la vida literaria, e incluso refiere que entre tales valoraciones se definen las jerarquías, elemento valioso para establecer prioridades promocionales.

Por tanto dicha gestión debe insertar tales conexiones y diversificar posibilidades entre la labor del crítico, el promotor y los autores que se desean promover, lo que implica destacar la pertinencia de la relación crítico-promotor dentro de las mediaciones indicadas, pues ambos aportan al proceso, aunque parezca que el primero labore más al interior del campo, y el segundo, actúe hacia el conjunto de la sociedad.

De tal manera, la Feria Internacional del Libro, las Lecturas de verano y el Festival del Libro y la Lectura en las universidades, se han convertido en importantes focos culturales y canales para la promoción literaria, por lo cual se impone intensificar y diversificar dichas opciones desde la programación.

Ante las nuevas significaciones que adquiere el consumo, el aumento de los precios de los libros y la necesidad de localizar recursos, Laguardia et al. (2010, p.10) se preguntan "¿Por qué no promover, desde la producción nacional, el soporte digital para el consumo de textos fundamentalmente literarios?", tal interrogante les permite argumentar el abaratamiento de los costos de producción, distribución, 
almacenaje, pero además la garantía de una mejor conservación y calidad de la publicación.

Lo anterior permite verificar el uso de las tecnologías de la información y las comunicaciones como potenciales espacios de promoción y creatividad para potenciar el talento artístico universitario.

Así en las prácticas vinculadas a las expresiones literarias pueden identificarse múltiples acciones, que caracterizan a unos y otros implicados en el proceso, en tanto se establece una correlación entre las actividades, la estructuración de prácticas específicas y la programación de los espacios culturales, que favorecen la política hacia la literatura y el libro.

En dicha correlación, hay elementos que adquieren validez propia en cuanto señalizan cuestiones organizativas, creativas y promocionales, que marcan determinadas prácticas culturales, cuyo accionar se despliega entre la creación y la gestión de su producción; cabe mencionar las prácticas creativas, críticas, promocionales e investigativas en relación directa con los géneros, sus formas y tradiciones literarias.

En tal sentido, este trabajo destaca la pertinencia del proyecto socioliterario, ya que integra a un conjunto de acciones cuya vigencia fortalece el sentido sostenible en cuanto al perfeccionamiento del talento literario universitario y su inserción en la vida literaria del entorno matancero.

Por consiguiente, se considera que la promoción literaria es un proceso que estimula no solo el disfrute y la apreciación crítica de las obras, las corrientes y tradiciones literarias, sino también la creatividad en las expresiones escriturales. Su mayor eficacia se alcanza con la interacción de autores, lectores, críticos y promotores, pues se enriquece la comunicación literaria, al tiempo que se aprovechan recursos y oportunidades del contexto cultural, con la finalidad de impulsar dicho proceso con acciones socializadoras, que propicien el consumo de la producción publicada, tanto en espacios públicos como virtuales.

\section{DESARROLLO}

El punto inicial de este proceso de estudio y sistematización de la vida literaria en la Universidad de Matanzas, lo constituyó la fundación del Taller de Creación Literaria Pablo Neruda en el curso 1996-1997. Desde aquellos años iniciales la creación literaria en la Universidad ha transcurrido por diversas etapas, pero es evidente que la nómina de jóvenes escritores ha aumentado no solamente en cuanto a cifras sino en la calidad y alcance de las propuestas literarias.

Cabe mencionar los nombres de algunos de los participantes de este enriquecedor proceso escriturario: Michel Diéguez, Pedro Romero, Juan Carlos de la Concepción, Dayán Peñate, Cecilia Soto, Dianelys Pérez, Ramón Fundora, Arián Sotolongo, Karel Bofill, Yeilén Delgado, Melissa Cabrera, Gloria L. Perera, Jeidi Suárez, Lianet Fundora, Yenli Lemus y Raúl Piad. 
Entre los años 2014 y 2015 se aprecia un crecimiento del talento literario en la Universidad de Matanzas, pero también una mayor participación en las actividades y extensiones de acciones culturales de gran impacto como la Feria Internacional del Libro, el Festival del Libro y la Lectura, así como en las diversas etapas de los Festivales de Artistas Aficionados.

Con vista a diseñar un proyecto sociocultural de mayor incidencia en la vida literaria matancera, se decidió aplicar un conjunto de técnicas para profundizar en la problemática creativa de los estudiantes incorporados.

En la fase diagnóstica, se emplearon diversas técnicas que fueron diseñadas a partir de los elementos que aportaron los estudios consultados. Aunque en los anexos se precisan detalles sobre cada una como parte de la aplicación, es necesario enfatizar que la investigación tuvo en cuenta la triangulación de las fuentes, debido a que la información se acopió por vías diversas y con distintos implicados, hasta lograr una mejor interpretación de los datos.

Las técnicas empleadas fueron la entrevista dirigida a los estudiantes incorporados, a integrantes de los jurados y a periodistas culturales; grupo de discusión con talleristas, lectores de la comunidad universitaria y críticos literarios de los medios de información provincial y la recepción crítica de trabajos presentados a los Festivales de Aficionados.

A continuación se muestra el análisis e interpretación de los datos arrojados por los instrumentos aplicados:

1.- Entrevista. Análisis e interpretación de los resultados.

Se realizaron tres entrevistas con el objetivo de profundizar en las dinámicas de la creación literaria estudiantil, sus experiencias y aspectos a mejorar. Fueron entrevistados estudiantes incorporados, integrantes de los jurados y periodistas culturales. Las guías elaboradas reflejan los aspectos que se tuvieron en cuenta.

Los resultados que aportó dicha técnica permitieron conocer el criterio de los entrevistados sobre las principales dificultades que se confrontan.

- Los estudiantes creadores plantean que a pesar de los contenidos que les aportan las asignaturas de letras aún carecen de conocimientos y habilidades para abordar los diferentes géneros literarios y sus variantes.

Por otro lado, reconocen que le dedican poco tiempo a la lectura, menos aún a la escritura y a la revisión detallada de los textos a concursar.

Indican que los resultados de la premiación se quedan en el reconocimiento moral por parte de la institución, pues no hay un accionar posterior que facilite la publicación de los trabajos en soportes que permitan su promoción, pero tampoco se despliegan intercambios con otros jóvenes interesados en la literatura.

Plantean además que carecen de condiciones para una labor creadora sistemática que les permita perfeccionar la labor creativa. 
Las respuestas no le conceden importancia a las facilidades que supone el empleo de las tecnologías de la información y las comunicaciones para socializar la producción premiada.

Tampoco reconocen que es imprescindible una formación teórico literaria y para ejecutar acciones promocionales desde la universidad.

Se entrevistaron jurados que han intervenido en los festivales a nivel de universidad y a nivel provincial, ellos refieren que las obras de calidad han aumentado y que el nivel universitario reclama un sistema de estímulos (premios) acorde a las nuevas realidades culturales del país.

Sin embargo, no identifican la publicación sistemática de los premios como una práctica que debe afrontar la universidad con sus propios recursos.

Los periodistas de los medios culturales plantean que los resultados en detalle de las acciones literarias y de los festivales les llegan con retraso.

Apuntan que sería positivo aprovechar más los espacios informativos de Juventud Rebelde, El Caimán Barbudo, Somos jóvenes y otras publicaciones, a fin de que se conozcan los nuevos talentos literarios.

2.- Grupo de discusión con talleristas, lectores de la comunidad universitaria y críticos literarios de los medios de información provincial. Análisis e interpretación de los resultados.

En los planteamientos se reconoce el papel que desempeñan los talleres en la preparación de los talentos a intervenir en los festivales, pero enfatizan que es una labor que exige condiciones materiales para lograr eficacia y estímulo en los estudiantes.

Destacaron que hay poca visión acerca del trabajo creativo con una perspectiva de género, lo que exige capacitación dado que en varias carreras predominan las escritoras.

Las respuestas enfatizan que hay desinterés por parte de la crítica respecto a la validez literaria del movimiento creativo de la universidad, aunque hay publicaciones como la revista Matanzas que acoge a veces textos ya premiados en los festivales.

Se evidenció la necesidad de priorizar espacios culturales fijos como el Portal de las Letras, cuyo prestigio garantice el acceso a la universidad de escritores profesionales de alta jerarquía estética.

3.- Recepción crítica de obras premiadas en los festivales (2013-2015). Análisis e interpretación de los resultados.

Para la búsqueda de recepciones se escogieron textos premiados en ediciones de los festivales a nivel provincial y nacional en el periodo 2013-2015, perteneciente a los creadores.

Ante la carencia de recepciones críticas específicas acerca de los autores seleccionados se decidió incorporar los apuntes de los jurados en las actas de los 
eventos identificados. En tal sentido, se pudo constatar la siguiente información de experto.

\section{Luces (poesía), de Melissa Cabrera García; Mensaje contra la espera}

(décima), de Lianet Fundora Armas; Nostalgias (cuento), de Raúl Piad Ríos.

En las valoraciones críticas son destacas las habilidades de los creadores en el uso del lenguaje figurado, la estructuración de los textos y el diseño de los personajes, no obstante se les sugiere seguir perfeccionando las obras e incorporar a sus lecturas autores cubanos más actuales.

\section{Huérfana de inspiración (poesía), de Gloria L. Perera Fundora; Bitácora}

(décima), de Lianet Fundora Armas; Insomnio (cuento), de Tania Gómez Barrios. Entre los aspectos críticos abordados se enfatiza la existencia de una unidad de contenido y forma, pero se insiste en la necesidad de evitar lugares comunes, la adjetivación, así como enriquecer más el lenguaje poético.

2015. El último round (poesía), de Náthaly Hernández Chávez; Monólogo (décima), de Lianet Fundora Armas; Mientras muere un canguro (cuento), de Guillermo Carmona Rodríguez.

En los referentes se insiste en una buena articulación de los significados, cierto dominio del lenguaje y usar en muchos casos acertadamente las figuras retóricas y el intertexto. Por otro lado, se destaca el uso de los recursos propios de la narrativa y el tratamiento de temas de actualidad en las propuestas, lo que incluye expresiones críticas sobre la realidad cotidiana.

Al comparar los registros y la información aportada por la entrevista, el grupo de discusión y la recepción crítica, se constató que se le concede poco tiempo a la revisión detallada de los textos producidos y a la lectura formativa, también que se carece de publicaciones sistemáticas en diversos soportes que permitan una promoción y socialización coherente dentro de la comunidad universitaria, la falta de intercambios con otros jóvenes interesados en la literatura.

La aplicación de los instrumentos descritos facilitaron no solamente identificar las dificultades de la problemática y darle tratamiento a las insatisfacciones de los jóvenes cultivadores, sino identificar fortalezas y oportunidades a fin de conformar un proyecto socioliterario desde el Taller de Creación Pablo Neruda (Ver anexos con las acciones para el periodo 2016-2018), que propicie un incremento sostenible de la creatividad entre los talleristas y el establecimiento de otras vías de socialización de las obras ya legitimadas por los festivales.

A partir de los requerimientos teóricos y literarios valorados, así como de las dificultades señaladas, se identificaron las principales fortalezas de la práctica escrituraria, pero también las oportunidades aportadas por el contexto cultural y la influencia de múltiples agentes de la vida literaria. 


\section{CONCLUSIONES}

La necesidad de repensar la práctica literaria creativa desde la universidad supone profundizar en el campo literario y en los múltiples agentes que se imbrican en dicha labor, lo que implica trasladarla al campo científico con la finalidad de construir una reflexión y un conocimiento para promover el cambio y su rearticulación al entorno sociocultural.

En tal sentido, es imprescindible diseñar las técnicas de investigación que mejor garanticen la búsqueda de una información eficaz para conocer las dinámicas internas de una práctica que permita promover su desarrollo sostenible en el tiempo a partir de una proyecto sociocultural, que incluya su propio sistema de evaluación.

El diseño de una promoción cultural en la universidad debe partir de un diálogo de saberes, que involucre a investigadores y expertos del mundo académico, pero también a personalidades del ámbito cultural y sus instituciones, como sujetos comunicadores de experiencias y buenas prácticas, lejos de toda superioridad o posición centrista, pues dichos acercamientos se configuran desde la diversidad y la apreciación crítica de una realidad social cada vez más compleja, en la cual los jóvenes talentos descubren no solo una forma de demostrar su creatividad, sino una vía para transformar y enriquecer la espiritualidad de los miembros de la comunidad universitaria y extrauniversitaria.

Por tanto, para lograr el desarrollo sostenible de la práctica literaria de los jóvenes talentos, será necesario configurar con visión estratégica los siguientes aspectos: Orientar el perfeccionamiento de dicha práctica a partir del debate crítico y profundo en torno al compromiso social del creador y las nuevas corrientes que caracterizan el campo literario.

Establecer formas novedosas de capacitación de los promotores culturales en la universidad, que incluyan los conocimientos, habilidades y técnicas que aportan las asignaturas y programas docentes desde una visión curricular y extracurricular, junto a saberes, habilidades y competencias que se generan en el entorno cultural y el campo académico.

La necesidad de diseñar los espacios de promoción intra y extrauniversitaria, a partir de una identidad propia respecto a la comunidad, que involucre a los jóvenes talentos como promotores específicos de sus expresiones literarias.

La investigación y la reflexión sistemática sobre estos temas y los resultados de prácticas promocionales en la universidad y en su entorno, deberán constituir en todo momento la garantía del proyecto socioliterario Taller de Creación Literaria Pablo Neruda y su proyección futura.

\section{Referencias}

AGUIRRE ROMERO, J. Ma . (2007). La incidencia de las Redes de comunicación en el Sistema literario. Recuperado 5/9/2007. <http://www.ucm.es/otros/especulo/ numero7/sistemal.htm>. 
ÁLVAREZ, L. y RAMOS RICO, J.F. (2003). Circunvalar el arte. La investigación cualitativa sobre cultura y arte. Santiago de Cuba: Editorial Oriente.

AMAYA QUINCOCES, C. (2008). Gestión de mercadotecnia en el arte. La Habana: Ediciones Unión.

ANDER-EGG, E. (1986). La promoción sociocultural en América Latina. Un estudio de casos en Costa Rica, Ecuador, México y Argentina. París: UNESCO.

BARRERA ENDERLE, V. (2014). La crítica en la América Latina actual, ¿de qué estamos hablando? (Un acercamiento al discurso crítico de Grínor Rojo). En Revista Casa de las Américas No. 277, octubre-diciembre.

BAYARDO, R. (2001). Cultura, artes y gestión. La profesionalización de la gestión cultural. Recuperado el 9 de noviembre del 2009: <www.cepi.us/posgrado/download. php? file=RBayardo.pdf\&type $>$.

BOURDIEU, p. (1990) El campo literario. Prerrequisitos críticos y principios de método. Criterios, La Habana, no 25-28, enero 1989-diciembre 1990, pp. 20-42.

BOWER, J.L. y DOZ (1978). Strategy formulation: a social and political process. En Hofer, C.H y Schendel, D. (Coord.), Strategy Management, Little Brown.

CASANOVAS, A. y CARCASSÉS, A. (2000). Acciones dinamizadoras de la participación de los cubanos en la cultura. En Ana Vera (comp.), Pensamiento y tradiciones populares: estudios de identidad cultural cubana y latinoamericana, (pp. 232-257). La Habana: Centro de Investigación y Desarrollo de la Cultura Cubana.

CHACÓN ZALDÍVAR, Carlos (2016). Estrategia de promoción de la décima escrita en Cuba: Estudio de caso del Concurso Iberoamericano Cucalambé, Tesis presentada en opción al grado de doctor en ciencias sobre arte, Instituto Superior de Arte, La Habana.

EDUARDO VÁZQUEZ, E. (2011). Epistemología o senderos hacia el conocimiento. Una aproximación desde la investigación cultural. 12 de octubre. (Comunicación personal).

ESPINA, M. (2004). Humanismo, totalidad y complejidad. El giro epistemológico en el pensamiento social y la conceptualización del desarrollo. En Linares et al., La participación. Diálogo y debate en el contexto cubano. La Habana: Centro de Investigación y Desarrollo de la Cultura Cubana Juan Marinello.

FREIRE, P. (1973). ¿Extensión o comunicación? La concientización en el medio rural. Buenos Aires: Siglo XXI.

GARCÍA CANCLINI, N. (1998). Políticas Culturales: De las identidades nacionales al espacio latinoamericano en Anales del Seminario Integración Económica e Industrias Culturales en América Latina y el Caribe, SELA/UNESCO/Convenio Andrés Bello y Gobierno de Bs. As, 30-31 de julio.

GUTIÉRREZ MENÉNDEZ, G.E. (1994). Teoría y práctica de la gestión cultural. La Habana: Centro Nacional de Superación para la Cultura. Colección Punto de Partida. 
HERNÁNDEZ LORENZO, M. (2011). Intervención en la II Jornada de la Cultura Cubana en Medios Digitales. Boletín Cultural Cubarte, (2011-11-17).

HERNÁNDEZ, L. (2014) Entre el saber y el hacer. La acción dialógica de la acción cultural, Veracruz, México: Instituto Veracruzano de la Cultura - Conaculta.

KARAM, T. (2006). "La comunicación literaria. Notas para un debate teórico" en

Revista Especulo 31, Madrid. UCM. Recuperado 21 de marzo 2008. En línea, disponible en: <http://www.ucm.es/info/especulo/numero31/comliter.html>.

LAGUARDIA, J, ORTEGA, D. y MOREJÓN, E. (2010). «Producción e industria editoriales: ¿qué pasa en el mundo, qué se hace en Cuba?, en Memorias. 20 Ferias

Internacionales del Libro de La Habana, (pp.146-170). La Habana: Editorial Científico-Técnica, Instituto Cubano del Libro.

LÓPEZ BORBÓN, L. (2015). "La gestión cultural como construcción de ciudadanía" en "Políticas culturales y construcción de ciudadanía", presentado en II Conferencia de la Cultura, Pamplona, España: Federación Estatal de Gestores Culturales.

MARKIEWICZ, H. (1983). La recepción y el receptor en las investigaciones literarias. Perspectivas y dificultades. Criterios, vol. 5/12, 3-19.

MENGUZZATO, M. (1989). Hacia la dirección estratégica. En: La dirección estratégica en el marco económico actual, CAM y Universidad de Alicante.

MINTZBERG, H. y WATERS, H. (1985). Of strategy delivered emergent. Strategy Management Journal, julio-septiembre.

NÁPOLES, E, PORTAL, R y DEL PINO, T. (2012). Comunicación y desarrollo: posibles articulaciones en el contexto cubano. Temas, n.71.La Habana, julio-septiembre.

RAUSELL KÖSTER, P., ABELEDO, R., CARRASCO, S. y MARTÍNEZ, J. (2007).

Cultura. Estrategia para el desarrollo local. Madrid: Dirección General de Relaciones Culturales y Científicas-AECI.

\section{ANEXOS}

\section{6}

\begin{tabular}{|c|c|c|c|c|c|}
\hline NO & ACTIVIDADES & MÉTODOS & FECHA & PARTICIPANTES & RESPONSABLE \\
\hline I & $\begin{array}{l}\text { Desarrollar el encuentro } \\
\text { mensual del Taller de Creación } \\
\text { Literaria Pablo Neruda. }\end{array}$ & $\begin{array}{l}\text { Trabajo en } \\
\text { colectivo }\end{array}$ & $\begin{array}{l}\text { Según } \\
\text { cronograma de } \\
\text { actividades } 2016\end{array}$ & Talleristas & $\begin{array}{l}\text { Coordinador del } \\
\text { Taller }\end{array}$ \\
\hline II & $\begin{array}{l}\text { Divulgar las mejores obras } \\
\text { escritas por los miembros del } \\
\text { Taller. } \\
\text { Publicar el Boletín Canímar dos } \\
\text { meses al año. }\end{array}$ & $\begin{array}{l}\text { Trabajo en } \\
\text { colectivo }\end{array}$ & $\begin{array}{l}\text { Meses de Abril y } \\
\text { Noviembre }\end{array}$ & $\begin{array}{l}\text { Talleristas Diseñador } \\
\text { Consejo de } \\
\text { redacción }\end{array}$ & Coordinador \\
\hline
\end{tabular}




\begin{tabular}{|c|c|c|c|c|c|}
\hline NO & ACTIVIDADES & MÉTODOS & FECHA & PARTICIPANTES & RESPONSABLE \\
\hline III & $\begin{array}{l}\text { Estimular la participación de } \\
\text { los miembros en concursos } \\
\text { nacionales: } \\
\text { Festival Provincial y Nacional } \\
\text { de Literatura de la FEU. } \\
\text { Encuentro Provincial de } \\
\text { Talleres Literarios de Matanzas. }\end{array}$ & $\begin{array}{l}\text { Intervención } \\
\text { personal }\end{array}$ & $\begin{array}{l}\text { Según fecha de } \\
\text { los Festivales de } \\
\text { Aficionados. } \\
\text { Según } \\
\text { cronograma de } \\
\text { la Dirección } \\
\text { Provincial de } \\
\text { Literatura }\end{array}$ & $\begin{array}{l}\text { Talleristas } \\
\text { Talleristas }\end{array}$ & $\begin{array}{l}\text { Coordinador y } \\
\text { Talleristas }\end{array}$ \\
\hline IV & $\begin{array}{l}\text { Efectuar lecturas y } \\
\text { presentaciones de libros: } \\
\text { Feria Internacional del Libro. } \\
\text { Festival Universitario del Libro } \\
\text { y la Lectura. }\end{array}$ & $\begin{array}{l}\text { Trabajo en } \\
\text { colectivo }\end{array}$ & Febrero-Marzo & $\begin{array}{l}\text { Talleristas y } \\
\text { estudiantes }\end{array}$ & $\begin{array}{l}\text { Coordinador } \\
\text { Consejo de } \\
\text { Promoción }\end{array}$ \\
\hline V & $\begin{array}{l}\text { Insertar obras de los talleristas } \\
\text { en proyectos de antología de } \\
\text { poesía matancera y cubana a } \\
\text { publicarse en Chile. }\end{array}$ & $\begin{array}{l}\text { Diálogo } \\
\text { con los } \\
\text { antologadores }\end{array}$ & $\begin{array}{l}\text { Noviembre- } \\
\text { Diciembre }\end{array}$ & Coordinador & Coordinador \\
\hline VI & $\begin{array}{l}\text { Profundizar en aspectos } \\
\text { teóricos y prácticos del proceso } \\
\text { escritural y literario. }\end{array}$ & $\begin{array}{l}\text { Seminarios } \\
\text { y actividades } \\
\text { prácticas }\end{array}$ & Todo el año & Estudiantes captados & $\begin{array}{l}\text { Coordinador del } \\
\text { Taller }\end{array}$ \\
\hline
\end{tabular}

\section{7}

\begin{tabular}{|c|c|c|c|c|c|}
\hline NO & ACTIVIDADES & MÉTODOS & FECHA & PARTICIPANTES & RESPONSABLE \\
\hline I & $\begin{array}{l}\text { Profundizar en aspectos } \\
\text { teóricos y prácticos del proceso } \\
\text { escritural y literario. }\end{array}$ & $\begin{array}{l}\text { Seminarios } \\
\text { y actividades } \\
\text { prácticas } \\
\end{array}$ & Todo el año & Estudiantes captados & $\begin{array}{l}\text { Coordinador del } \\
\text { Taller }\end{array}$ \\
\hline II & $\begin{array}{l}\text { Desarrollar el encuentro } \\
\text { mensual del Taller de Creación } \\
\text { Literaria Pablo Neruda. } \\
\text { Capacitar a integrantes del } \\
\text { colectivo para atender a talleres } \\
\text { literarios de las comunidades } \\
\text { (Cárdenas y Limonar). } \\
\end{array}$ & $\begin{array}{l}\text { Trabajo en } \\
\text { colectivo }\end{array}$ & $\begin{array}{l}\text { Según } \\
\text { cronograma de } \\
\text { actividades } 2017 \\
\text { Marzo, Junio y } \\
\text { Nov. }\end{array}$ & Talleristas & Coordinador \\
\hline III & $\begin{array}{l}\text { Divulgar las mejores obras } \\
\text { escritas por los miembros del } \\
\text { Taller. } \\
\text { Publicar el Boletín El Iris como } \\
\text { principal propuesta literaria. } \\
\text { Publicar plegables } \\
\text { promocionales en ocasión } \\
\text { del Día del Idioma Español } \\
\text { en Cuba y para el Festival } \\
\text { Universitario del Libro y la } \\
\text { Lectura. }\end{array}$ & $\begin{array}{l}\text { Trabajo en } \\
\text { colectivo }\end{array}$ & $\begin{array}{l}\text { Meses de Abril y } \\
\text { Noviembre }\end{array}$ & $\begin{array}{l}\text { Talleristas Diseñador } \\
\text { Consejo de } \\
\text { redacción }\end{array}$ & Coordinador \\
\hline IV & $\begin{array}{l}\text { Efectuar lecturas y } \\
\text { presentaciones de libros: Feria } \\
\text { Internacional del Libro. } \\
\text { Festival Universitario del Libro } \\
\text { y la Lectura. } \\
\text { Jornada Científica de la Facultad } \\
\text { y a nivel de Universidad. }\end{array}$ & $\begin{array}{l}\text { Trabajo en } \\
\text { colectivo }\end{array}$ & $\begin{array}{l}\text { Febrero-Marzo } \\
\text { Noviembre }\end{array}$ & $\begin{array}{l}\text { Talleristas y } \\
\text { estudiantes }\end{array}$ & $\begin{array}{l}\text { Coordinador } \\
\text { Consejo de } \\
\text { Promoción }\end{array}$ \\
\hline
\end{tabular}




\begin{tabular}{|c|c|c|c|c|c|}
\hline NO & ACTIVIDADES & MÉTODOS & FECHA & PARTICIPANTES & RESPONSABLE \\
\hline $\mathbf{V}$ & $\begin{array}{l}\text { Propiciar la escritura de } \\
\text { comentarios críticos acerca } \\
\text { de las novedades literarias } \\
\text { publicadas, según la selección de } \\
\text { los talleristas. }\end{array}$ & $\begin{array}{l}\text { Trabajo } \\
\text { individual }\end{array}$ & Todo el curso & Talleristas & Coordinador \\
\hline VI & $\begin{array}{l}\text { Estimular la participación de } \\
\text { los miembros en concursos } \\
\text { nacionales: } \\
\text { Festival de Literatura de la } \\
\text { FEU a nivel Universidad y de } \\
\text { Provincial. } \\
\text { Encuentro Provincial de } \\
\text { Talleres Literarios de Matanzas } \\
2017 \text {. } \\
\text { Concurso de relato breve El } \\
\text { dinosaurio (Centro Onelio Jorge } \\
\text { Cardoso). }\end{array}$ & $\begin{array}{l}\text { Intervención } \\
\text { personal }\end{array}$ & $\begin{array}{l}\text { Según fecha de } \\
\text { los Festivales de } \\
\text { Aficionados. } \\
\text { Según } \\
\text { cronograma de la } \\
\text { Dirección } \\
\text { Provincial de } \\
\text { Cultura }\end{array}$ & $\begin{array}{l}\text { Talleristas } \\
\text { Talleristas }\end{array}$ & $\begin{array}{l}\text { Coordinador y } \\
\text { Talleristas }\end{array}$ \\
\hline
\end{tabular}

\section{8}

\begin{tabular}{|c|c|c|c|c|c|}
\hline NO & ACTIVIDADES & MÉTODOS & FECHA & PARTICIPANTES & RESPONSABLE \\
\hline I & $\begin{array}{l}\text { Profundizar en aspectos } \\
\text { teóricos y prácticos del proceso } \\
\text { escritural y literario. }\end{array}$ & $\begin{array}{l}\text { Seminarios } \\
\text { y actividades } \\
\text { prácticas }\end{array}$ & Todo el año & Estudiantes captados & $\begin{array}{l}\text { Coordinador del } \\
\text { Taller }\end{array}$ \\
\hline II & $\begin{array}{l}\text { Desarrollar el encuentro } \\
\text { mensual del Taller de } \\
\text { Creación Literaria Pablo } \\
\text { Neruda. } \\
\text { Capacitar a integrantes del } \\
\text { colectivo para atender a talleres } \\
\text { literarios de las comunidades } \\
\text { (Cárdenas y Limonar). }\end{array}$ & $\begin{array}{l}\text { Trabajo en } \\
\text { colectivo }\end{array}$ & $\begin{array}{l}\text { Según } \\
\text { cronograma de } \\
\text { actividades } 2018 \\
\text { Marzo, Junio y } \\
\text { Nov. }\end{array}$ & Talleristas & Coordinador \\
\hline III & $\begin{array}{l}\text { Divulgar las mejores obras } \\
\text { escritas por los miembros del } \\
\text { Taller. } \\
\text { Publicar el Boletín El Iris como } \\
\text { principal propuesta literaria. } \\
\text { Publicar plegables } \\
\text { promocionales en ocasión del } \\
\text { Día } \\
\text { del Idioma Español en Cuba y } \\
\text { para el Festival Universitario del } \\
\text { Libro y la Lectura. }\end{array}$ & $\begin{array}{l}\text { Trabajo en } \\
\text { colectivo }\end{array}$ & $\begin{array}{l}\text { Marzo, Abril y } \\
\text { Noviembre }\end{array}$ & $\begin{array}{l}\text { Talleristas Diseñador } \\
\text { Consejo de } \\
\text { redacción }\end{array}$ & Coordinador \\
\hline IV & $\begin{array}{l}\text { Crear el sitio WEB del Taller } \\
\text { de Creación Literaria Pablo } \\
\text { Neruda. }\end{array}$ & $\begin{array}{l}\text { Trabajo en } \\
\text { colectivo }\end{array}$ & $\begin{array}{l}\text { Marzo, Abril y } \\
\text { Noviembre }\end{array}$ & $\begin{array}{l}\text { Talleristas, diseñador } \\
\text { y consejo de } \\
\text { redacción }\end{array}$ & Coordinador \\
\hline IV & \begin{tabular}{|l|} 
Efectuar lecturas y \\
presentaciones de libros: Feria \\
Internacional del Libro. \\
Festival Universitario del Libro \\
y la Lectura. \\
Jornada Científica de la Facultad \\
y a nivel de Universidad. \\
\end{tabular} & $\begin{array}{l}\text { Trabajo en } \\
\text { colectivo }\end{array}$ & $\begin{array}{l}\text { Febrero-Marzo } \\
\text { Noviembre }\end{array}$ & $\begin{array}{l}\text { Talleristas y } \\
\text { estudiantes }\end{array}$ & $\begin{array}{l}\text { Coordina Consejo } \\
\text { de Promoción }\end{array}$ \\
\hline $\mathbf{V}$ & $\begin{array}{l}\text { Propiciar la escritura de } \\
\text { comentarios críticos acerca } \\
\text { de las novedades literarias } \\
\text { publicadas, según la selección } \\
\text { de los talleristas. }\end{array}$ & $\begin{array}{l}\text { Trabajo } \\
\text { individual }\end{array}$ & Todo el curso & Talleristas & Coordinador \\
\hline
\end{tabular}




\begin{tabular}{|c|c|c|c|c|c|}
\hline NO & ACTIVIDADES & MÉTODOS & FECHA & PARTICIPANTES & RESPONSABLE \\
\hline VI & $\begin{array}{l}\text { Estimular la participación de } \\
\text { los miembros en concursos } \\
\text { nacionales: } \\
\text { Festival de Literatura de la FEU } \\
\text { a nivel Nacional. Encuentro } \\
\text { Provincial de Talleres Literarios } \\
\text { de Matanzas } 2018 . \\
\text { Concurso de relato breve El } \\
\text { dinosaurio (Centro Onelio } \\
\text { Jorge Cardoso). } \\
\text { Concurso de Cuento Juan Rulfo }\end{array}$ & $\begin{array}{l}\text { Intervención } \\
\text { personal }\end{array}$ & $\begin{array}{l}\text { Según fecha de } \\
\text { los Festivales de } \\
\text { Aficionados. } \\
\text { Según } \\
\text { cronograma de } \\
\text { la Dirección } \\
\text { Provincial de } \\
\text { Cultura }\end{array}$ & $\begin{array}{l}\text { Talleristas } \\
\text { Talleristas }\end{array}$ & $\begin{array}{l}\text { Coordinador y } \\
\text { Talleristas }\end{array}$ \\
\hline
\end{tabular}

